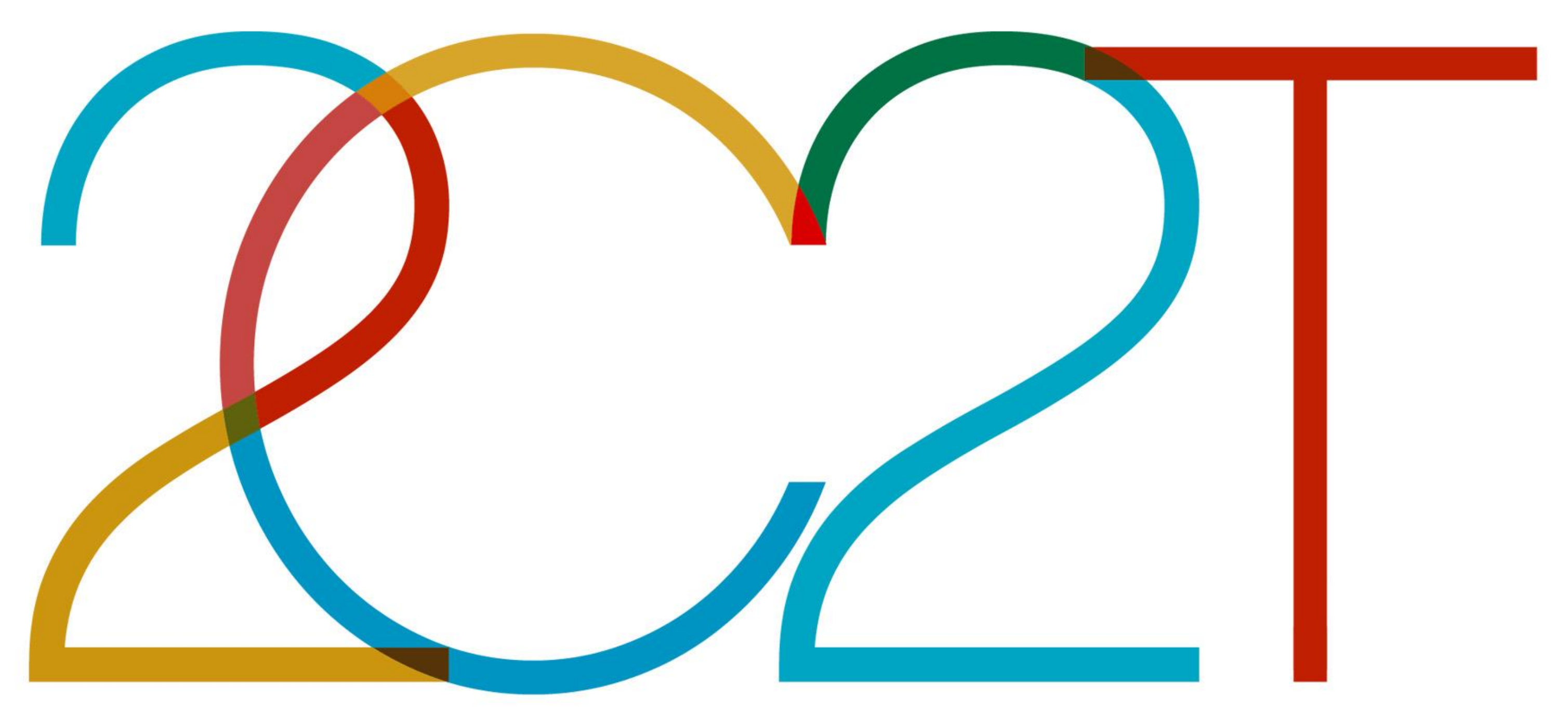

CENTRO DECIÊNCIAE
TECNOLOGIATEXXTIL

www.2c2t.uminho.pt

\title{
Flexible, biodegradable LL37- anchored poly(vinyl alcohol)/cellulose acetate films for enhanced infection control
}

Helena P. Felgueiras*, Marta A. Teixeira, Tânia D. Tavares, Natália C. Homem, Marta O. Teixeira, Andrea Zille, Joana C. Antunes, M. Teresa P. Amorim Centro de Ciência e Tecnologia Têxtil (2C2T), Universidade do Minho, Portugal *helena.felgueiras@2c2t.uminho.pt

Introduction

Wound care is a growing industry that lately has been facing multiple challenges due to the increasing health care costs, aging of population, appearance of antibiotic-resistant pathogens, and rise in the incidence of chronic diseases. Unlike acute wounds which heal in a predictable amount of time following the stages of healing, chronic wounds (CW) often fail to progress past the inflammatory phase, increasing costs and healing time. Bioactive dressings that incorporate drugs/antibiotics or bioactive molecules in their formulation have been suggested as alternatives to the conventional gauzes and foams. Here, we propose the combination of poly(vinyl alcohol) (PVA) and cellulose acetate (CA), both biodegradable and biocompatible polymers, for the production of films processed via a new method that combines principles from solvent casting and phase inversion, and modified with the antimicrobial peptide (AMP) LL37, as a new active solution.

\section{PVA/CA Film Production}

Materials: PVA, Mw 72,000 and 88\% hydrolyzed, and $\mathrm{Ca}$, Mn 30,000 and $39.8 \mathrm{wt} . \%$ acetyl groups; dimethyl formamide (DMF) as solvent coagulation bath of sodium sulfate $\left(\mathrm{Na}_{2} \mathrm{SO}_{4}\right)$ and sodium hydroxide $(\mathrm{NaOH})$

Method: Solvent Casting followed by Phase-Inversion
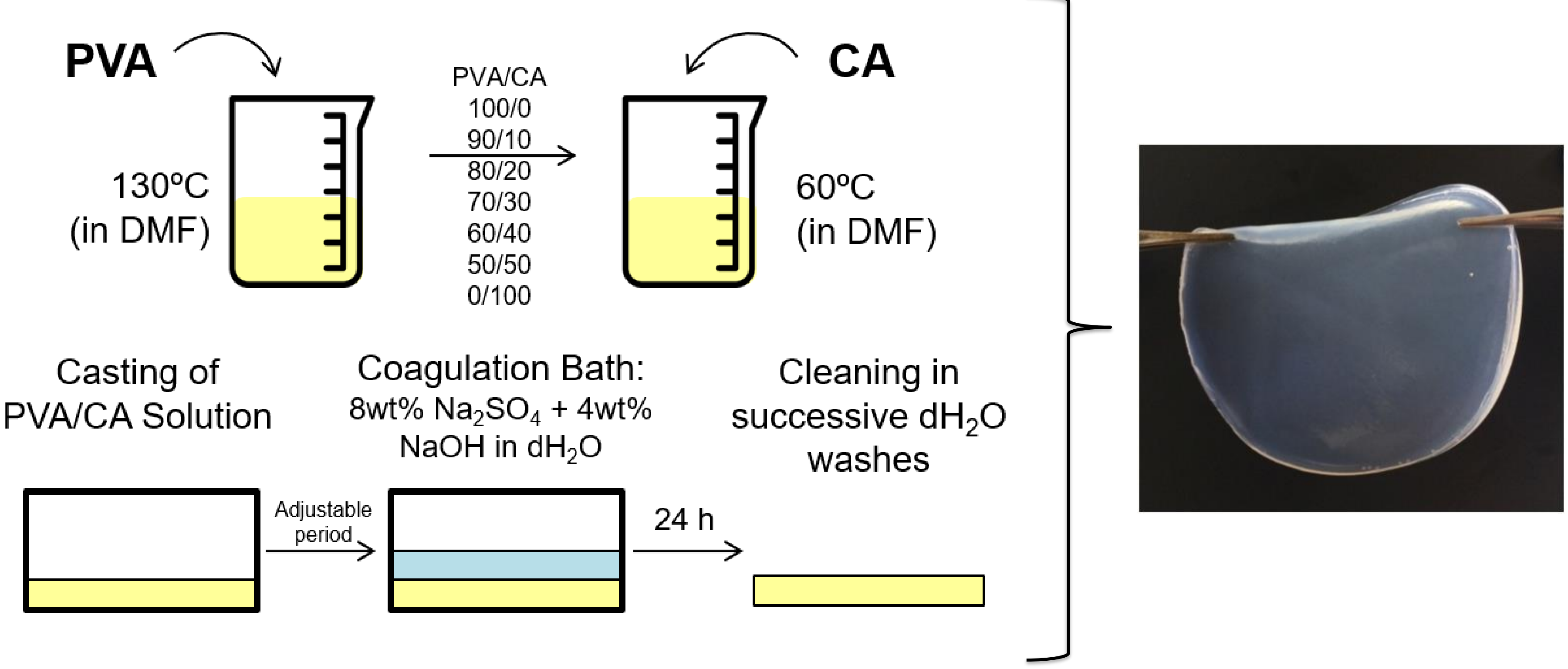

PVA/CA Films Characterization

1) Fourier-Transformed Infrared Spectroscopy with Attenuated Total Reflectance (ATR-FTIR)

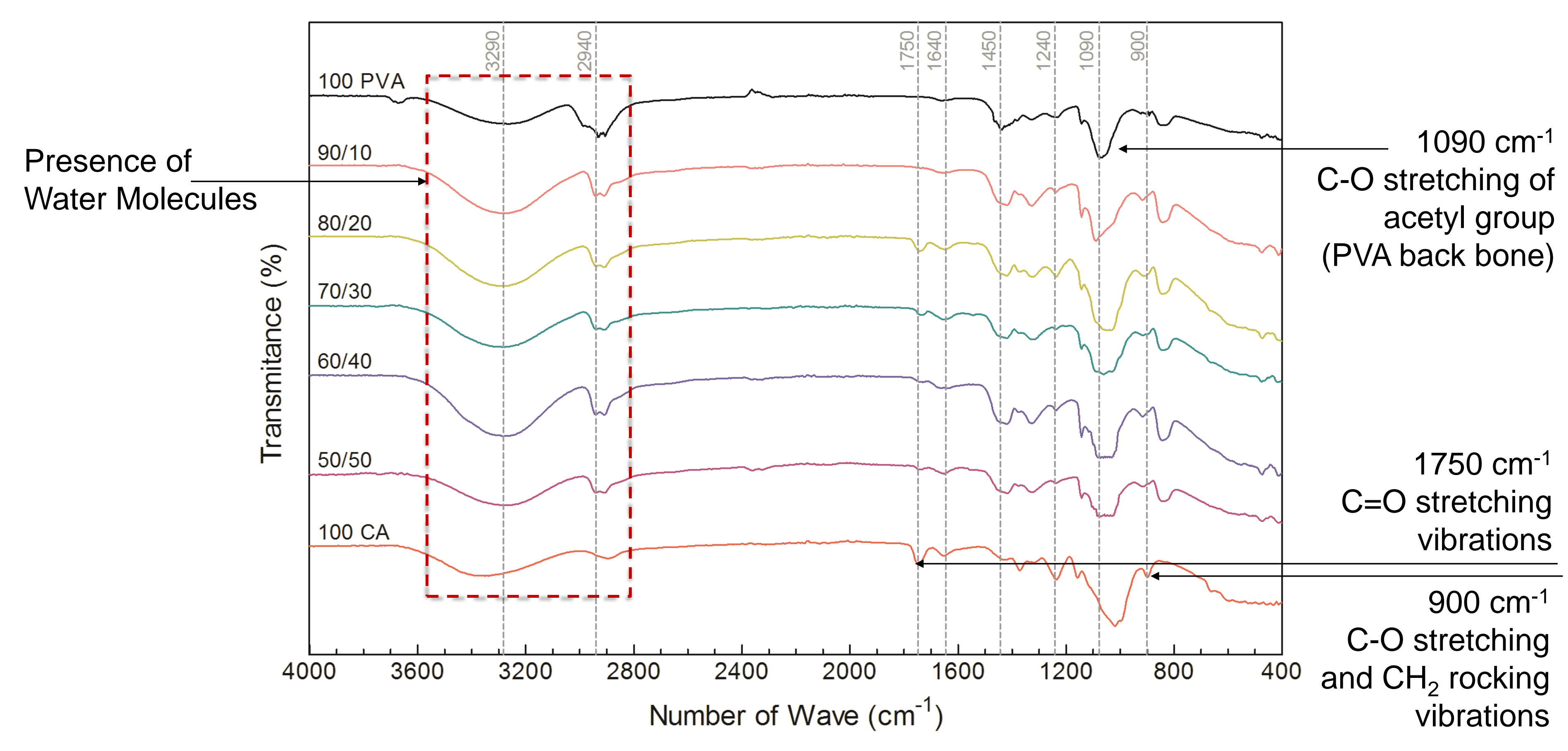

2) Tensile Strength, Elongation, Porosity and Swelling

\begin{tabular}{lccc|c}
\hline Films & $\begin{array}{c}\text { Breaking } \\
\text { Strength } \\
(\mathbf{N} \pm \text { SD) }\end{array}$ & $\begin{array}{c}\text { Elongation at } \\
\text { Break } \\
(\% \pm \text { SD) }\end{array}$ & $\begin{array}{c}\text { Porosity } \\
(\% \pm \text { SD) }\end{array}$ & $\begin{array}{c}\text { Degree of } \\
\text { Swelling } \\
(\% \pm \text { SD) }\end{array}$ \\
\hline $\mathbf{1 0 0 ~ P V A ~}$ & $3.24 \pm 0.03$ & $253.53 \pm 26.99$ & $29.07 \pm 5.12$ & $89.87 \pm 0.95$ \\
$\mathbf{9 0 / 1 0}$ & $2.56 \pm 0.14$ & $247.00 \pm 47.27$ & $30.90 \pm 2.43$ & $89.26 \pm 0.47$ \\
$\mathbf{8 0 / 2 0}$ & $2.52 \pm 0.25$ & $244.47 \pm 23.26$ & $33.40 \pm 3.79$ & $88.35 \pm 0.85$ \\
$\mathbf{7 0 / 3 0}$ & $1.49 \pm 0.18$ & $244.20 \pm 39.78$ & $37.52 \pm 6.81$ & $88.12 \pm 0.79$ \\
$\mathbf{6 0 / 4 0}$ & $1.48 \pm 0.15$ & $222.13 \pm 48.87$ & $44.92 \pm 2.15$ & $89.01 \pm 0.56$ \\
$\mathbf{5 0 / 5 0}$ & $1.28 \pm 0.20$ & $201.87 \pm 41.17$ & $52.99 \pm 4.95$ & $89.21 \pm 1.15$ \\
\hline $\mathbf{1 0 0} \mathbf{C A}^{*}$ & - & - & $91.83 \pm 14.62$ & $89.62 \pm 1.00$ \\
\hline
\end{tabular}

${ }^{*}$ Paper-like consistency, unable to explore mechanically.

LL37 Functionalization

"Graft to" methodology using poly(dopamine) (pDOPA) as binding agent. Vancomycin was used as control antibiotic.

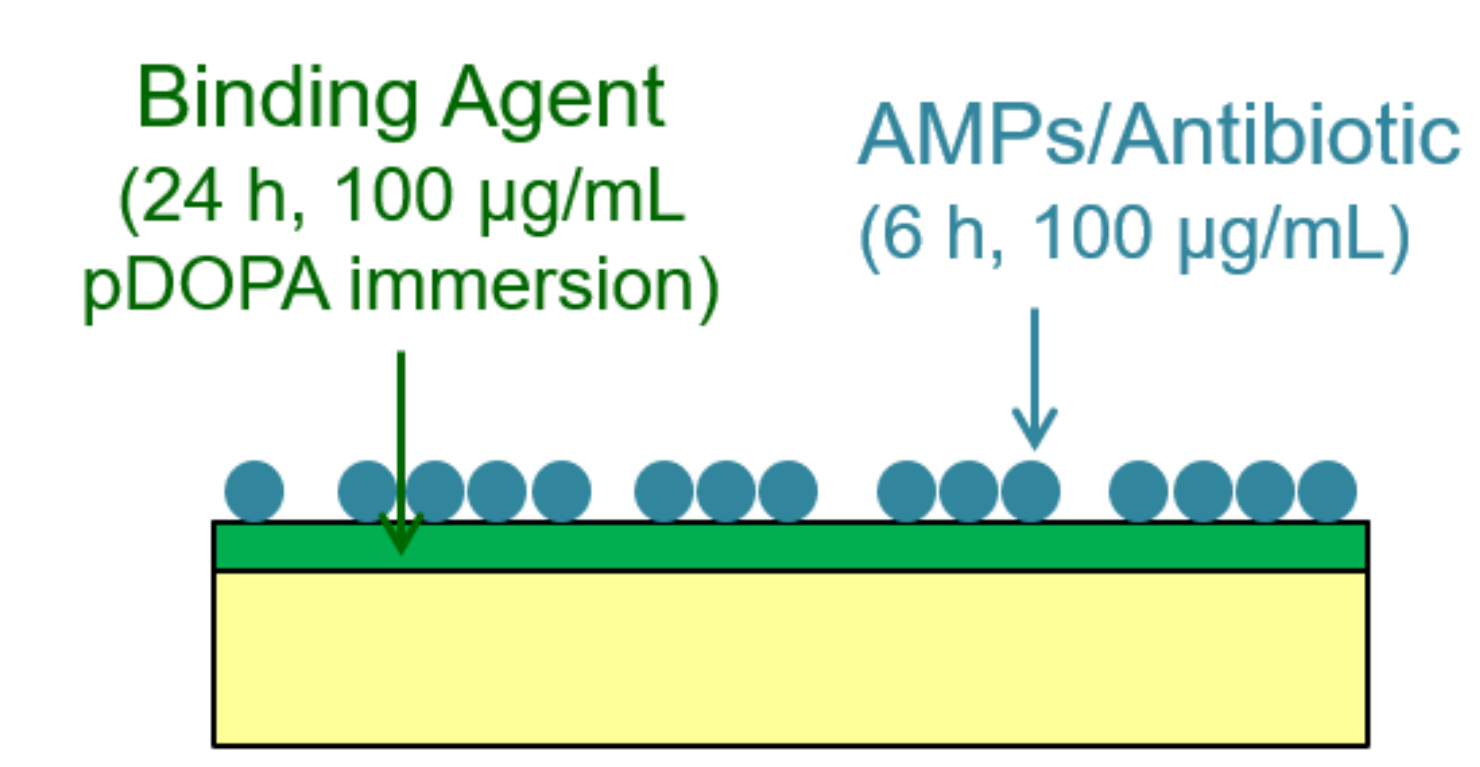

Antimicrobial Action

Shake Flask Method (ASTM-E2149-01)

Initial Bacteria Concentration: $1 \times 10^{7} \mathrm{CFUs} / \mathrm{mL}$ in PBS
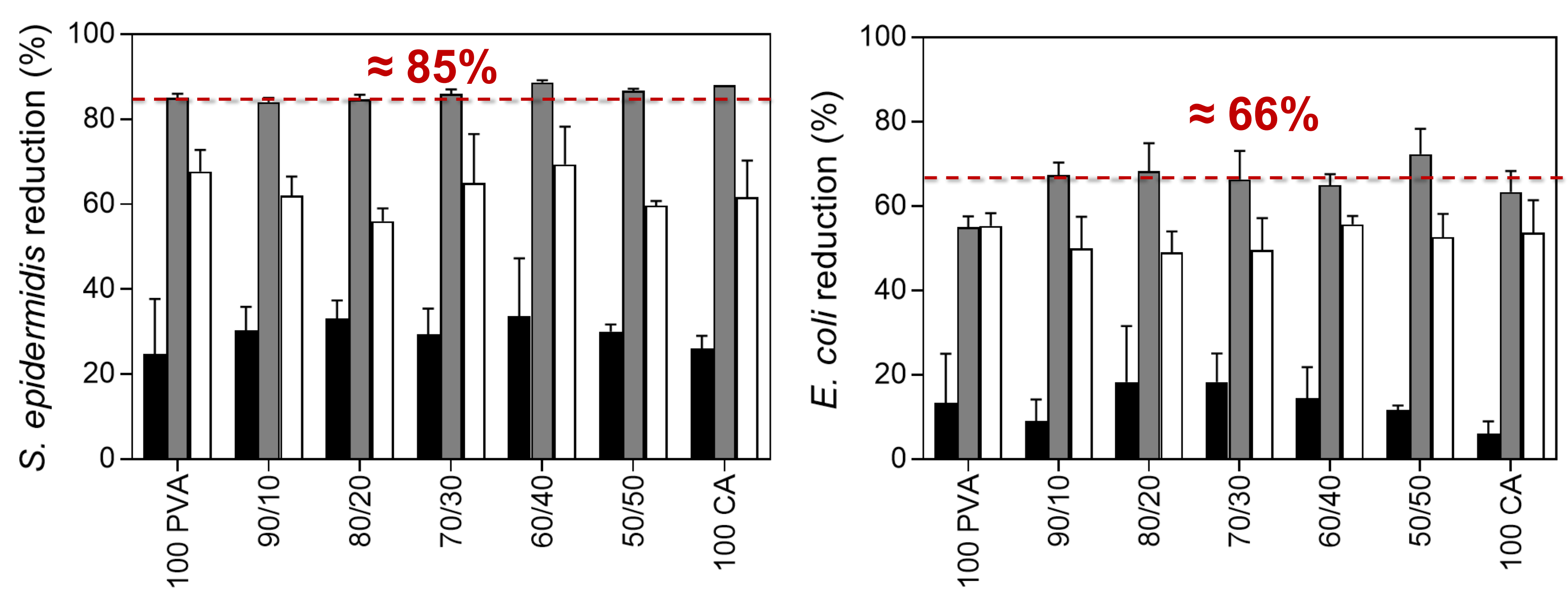

Clotting Time

Lee-White Method

Re-calcified Human Plasma $+1 \mathrm{M} \mathrm{CaCl}_{2}$ at $20 \mathrm{mM}\left(37^{\circ} \mathrm{C}\right)$

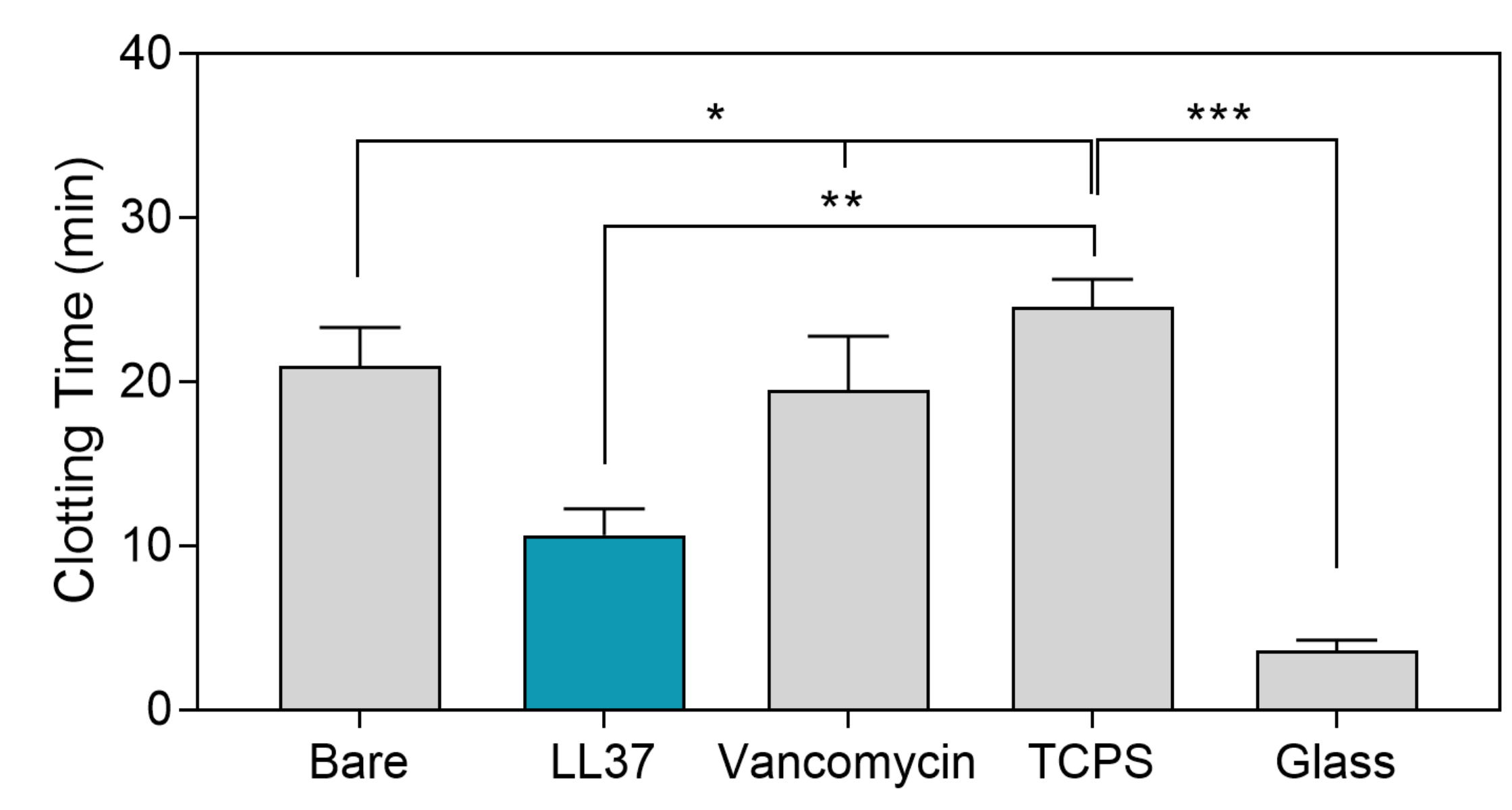

Conclusions: The potential of LL37 functionalized PVA/CA films for prospective wound-healing applications was demonstrated. For more details please refer to DOI: 10.1002/app.48626 